\title{
Risk-averse firms in oligopoly
}

\begin{abstract}
Marcus Asplund*
Stockholm School of Economics

SSE/EFI Working Paper Series in Economics and Finance No. 69

Revised version: February 2000

$\underline{\text { Abstract }}$

Does risk aversion lead to softer or fiercer competition? To give a complete answer, I provide a framework that can accommodate a wide range of alternative assumptions regarding the nature of competition and types of uncertainty. I show how more risk aversion will influence a firm's best response strategies, and that competition is unambiguously softer only in case of marginal cost uncertainty. In contrast to risk neutrality, the best response strategies depend on the level of fixed costs. This fact is extended to cover strategic investment models, and to analyse the importance of accumulated profits. I conclude by a discussion of how it is possible to test for risk-averse behaviour in oligopoly by conditioning on the type of uncertainty.
\end{abstract}

Keywords: Oligopoly; risk aversion; fixed costs; strategic investment; second order stochastic dominance; background risk; market risk.

JEL codes: D43; D81; L13; L21.

\footnotetext{
* Correspondence to: Marcus Asplund, Department of Economics, Stockholm School of Economics, Box 6501, S-113 83 Stockholm, Phone: +46-8-7369642, Fax: 46-8-313207, E-mail: nema@hhs.se. I wish to thank Richard Caves, Tore Ellingsen, Richard Friberg, Rickard Sandin, John Sutton, and seminar participants at E.A.R.I.E., Harvard University and Stockholm School of Economics for valuable comments. Suggestions by two anonymous referees greatly improved the paper. The usual disclaimer applies, however. Financial support from The Swedish Competition Authority and Jan Wallanders and Tom Hedelius Foundation is gratefully acknowledged.
} 


\section{Introduction}

A standard assumption in oligopoly theory is that firms are risk-neutral. However, there are several reasons for why firms may act as if they were risk-averse. Some of the factors that can be invoked are non-diversified owners, liquidity constraints, costly financial distress, and nonlinear tax systems. And even if owners themselves wish to maximise expected profits, delegation of control to a risk-averse manager, whose payment is linked to firm performance, may cause the firm to behave in a risk-averse manner. Empirically, the reluctance to bear risk is evidenced by the extent of corporate hedging activity (see e.g. Géczy et al., 1997, Tufano, 1996, and Nance et al., 1993). In spite of this, surprisingly little work has focused on the effects of risk aversion on competition. In particular, there has been very little effort spent on trying to derive empirically testable predictions regarding the effects of risk aversion on competition.

Altering the assumption of risk-neutrality has several implications for the product market competition. Early works examined perfect competition and monopoly settings. Pioneering analyses by Baron (1970) and Sandmo (1971) show how increased uncertainty about price lowers the quantity produced in perfectly competitive markets. In a monopoly framework, Baron (1971) and Leland (1972) derived similar results. Some questions that been addressed in an oligopoly framework include price leadership (Holthausen, 1979); information sharing (Hviid, 1989, and Kao and Hughes, 1993); product differentiation (Tessiotore, 1994); the Bertrand paradox (Wambach, 1999); locational choice (Mai et al., 1993); and equilibrium market structure (Appelbaum and Katz, 1986, and Haruna, 1996). Other studies have considered how the presence of futures and forwards markets may influence competition (Eldor and Zilcha, 1990, and Hughes and Kao, 1997), or the effects of hedging strategies and investment (Froot et al., 1993). Common to previous works is that they have employed specific assumptions on the nature of competition and uncertainty (e.g. Cournot competition with demand uncertainty). It is widely accepted, however, that many predictions from oligopoly models are sensitive to the fine details (often very difficult, if not 
impossible, to observe in practice) and it therefore seems appropriate to ask whether some results can be empirically validated.

In this paper I present a general framework to study the strategy choice of risk-averse firms. I consider how the nature of competition interacts with the type of uncertainty firms meet, which is found to be crucial in deriving predictions on the intensity of competition between risk-averse firms. The key assumption that I need is that profits and marginal profits are monotone in the realisation of uncertainty over the relevant set of strategies; a property that is satisfied by most common forms of uncertainty and profit functions. Given that uncertainty conforms to this, no distributional assumptions are made other than a bounded support.

The key intuition behind the effects of risk aversion is that firms gives relatively greater weight to realisations where profits are low. Its best response strategies are therefore geared towards relatively good performance in low profit states. For example, profits are low in states where marginal costs are high. In order to limit exposure to these realisations the risk-averse firm wishes to restrict output. This corresponds to low best response quantities, or high best response prices. With demand uncertainty, profits are low in states where demand is low. The risk-averse firm can insure against these cases by best response strategies that perform well in low demand states. Such strategies will involve low quantities, or low prices. An important result is that competition will be unambiguously softer only with marginal cost uncertainty. With demand uncertainty, risk aversion makes quantity competition softer but price competition fiercer.

In contrast to previous works on risk-averse oligopolies I allow for decreasing absolute risk aversion. If the objective function has this property then fixed costs influence the bestresponse strategies by increasing risk aversion. I extend this logic to analyse the effectiveness of strategic investments in capacity, and the importance of accumulated profits. Further, I examine to what extent more risk influences the best response functions. The paper concludes with remarks on available evidence, and suggests empirical tests for strategic effects of risk aversion. 
At this point, I wish to emphasize that although the presentation refers to situations where uncertainty is about demand/costs conditions and firms use prices/quantities as their strategic variables, the framework can accommodate many different situations where riskaverse firms compete. In fact, much of the same intuition carries over to cases where riskaverse firms are choosing among risky strategies such as $R \& D$ programmes, advertising campaigns, and capacity investments.

\section{The model}

The objective of each firm is to maximize its von Neuman - Morgenstern expected utility, $V^{i}=E U^{i}\left[W^{i}\right]$. The uncertain final wealth is $W^{i}=w^{i}+\pi^{i}-f^{i}$, where $w^{i}$ is initial wealth, $\pi^{i}$ is uncertain net operating profits, and $f^{i} \geq 0$ is fixed costs of production. The utility function is twice continuously differentiable and concave, $U_{W^{i}}^{i}>0$ and $U_{W^{i} W^{i}}^{i} \leq 0$. To simplify the exposition, I consider a market where two firms simultaneously choose their strategies. All parameters of the model are common knowledge to the firms. ${ }^{1}$ The operating profits of firm i is a twice continuously differentiable function of its strategy, $s^{i}$, and the strategy of firm $\mathrm{j}, s^{j}$ (throughout the paper $\mathrm{i} \neq \mathrm{j}$ ). The profit function is assumed to be concave, $\pi_{s^{i} s^{i}}^{i}<0$. There is, except in Section 3.3.1, a single source of uncertainty with a continuous, or discrete distribution on a bounded support, $\varepsilon \in(\underline{\varepsilon}, \bar{\varepsilon}) .^{2}$ To save on notation, arguments in functions will be suppressed when there is no risk of confusion and $U_{\pi^{i}}^{i}$ refers to $U_{W^{i}}^{i} W_{\pi^{i}}^{i}$.

Differentiating the objective function, $V^{i}$, w.r.t. $s^{i}$ yields the first-order condition

\footnotetext{
${ }^{1}$ Even though it is unrealistic to believe that competitors exactly know each other's utility function, it is not unreasonable to assume that firms in concentrated markets have a clear idea about their rivals' attitude towards risk. As mentioned in the introduction, some factors that can influence the objective function are observable to outsiders (e.g., ownership structure, degree of diversification, and financial situation).

2 The model abstracts from problems that arise when the owner/manager holds other assets, whose returns are correlated with the profits. For works that incorporate such aspects see Bughin (1999), Harris (1986) and Tessiotore (1994).
} 


$$
V_{s^{i}}^{i}=E U_{\pi^{i}}^{i} \pi_{s^{i}}^{i}=0
$$

To ensure that a unique stable Nash equilibrium (NE) exists I will assume that $V_{s^{i} s^{i}}^{i} V_{s^{j} s^{j}}^{j}-V_{s^{i} s^{j}}^{i} V_{s^{j} s^{i}}^{j}>0$, (see Dixit, 1986).

Let firm i's best-response function be $b^{i}\left(s^{j}\right)$, such that $s^{i}=b^{i}\left(s^{j}\right)$ satisfies (1) for a given $s^{j}$. The NE strategies, denoted $s^{i^{*}}$ and $s^{j^{*}}$, satisfies $s^{i^{*}}=b^{i}\left(s^{j^{*}}\right)$ and $s^{j^{*}}=b^{j}\left(s^{i^{*}}\right)$. The slope of the best-response function, obtained by differentiating (1) w.r.t. $s^{i}$ and $s^{j}$, is $b_{s^{j}}^{i}=-V_{s^{i} s^{j}}^{i} / V_{s^{i} s^{i}}^{i}$, where $V_{s^{i} s^{i}}^{i}<0$ from the second-order condition. In the terminology of Bulow et al. (1985), $s^{i}$ and $s^{j}$ are strategic substitutes if best-response functions are downward sloping, $V_{s^{i} s^{j}}^{i}<0$, and strategic complements if best-response functions are upward sloping, $V_{s^{i} s^{j}}^{i}>0$. Although I will informally refer to the strategies as "quantities" and "prices" for strategic substitutes and strategic complements, respectively, the framework applies equally well to other strategic choices (e.g., R\&D and advertising expenditures, and capacity investments). ${ }^{3}$

To give the intuition of how risk aversion influences firm i's strategy choice it is useful to rewrite (1), by applying the property $\operatorname{Cov}\left(U_{\pi^{i}}^{i}, \pi_{s^{i}}^{i}\right)=E U_{\pi^{i}}^{i} \pi_{s^{i}}^{i}-E U_{\pi^{i}}^{i} E \pi_{s^{i}}^{i}$, as

$$
E \pi_{s^{i}}^{i}+\frac{\operatorname{Cov}\left(U_{\pi^{i}}^{i}, \pi_{s^{i}}^{i}\right)}{E U_{\pi^{i}}^{i}}=0
$$

The denominator in the second term is positive, and clearly if firm i is risk-neutral then the covariance term is zero (the marginal utility is constant, and thereby independent of marginal profits). With decreasing marginal utility, in contrast, higher profits yield lower marginal utilities. The question is therefore how profits and marginal profits are related.

\footnotetext{
3 Just as in the case with risk-neutrality, it is possible to construct cases where firms set quantities (prices) but where the demand and cost functions make the strategies strategic complements (substitutes) over some range. For ease of exposition, here it is assumed that the best response functions are both either positive, or negative over the relevant range of strategies.
} 
At this point, I make one further assumption: profits and marginal profits are monotone in $\varepsilon$ for $\forall s^{i}, s^{j}$. The condition, for a continuous distribution of $\varepsilon$, is summarized as ${ }^{4}$

$$
\left\{\begin{array}{l}
\pi_{\varepsilon}^{i}\left(s^{i}, s^{j}, \varepsilon\right)>0 \text { for } \forall s^{i}, s^{j}, \text { and either } \\
\pi_{s_{\varepsilon}}^{i}\left(s^{i}, s^{j}, \varepsilon\right)>0 \text { for } \forall s^{i}, s^{j}, \text { which is denoted } \rho^{i}>1 ; \text { or } \\
\pi_{s_{\varepsilon} i^{i}}\left(s^{i}, s^{j}, \varepsilon\right)<0 \text { for } \forall s^{i}, s^{j}, \text { which is denoted } \rho^{i}<1 .
\end{array}\right.
$$

(A1) greatly simplifies the treatment of risk-averse firms in oligopoly. For $\rho^{i}>0$, realisations with high profits (and thereby low marginal utilities) have high marginal profits. Conversely, realisations with low profits (and, correspondingly, high marginal utilities) have low marginal profits. For $\rho^{i}<0$, the reverse is true (i.e., realisations with high (low) profits have low (high) marginal profits). I will refer to the first case as a positive correlation between profits and marginal profits, and the second case as a negative correlation. States with low profits are low (high) are 'low' or 'bad' ('high' or 'good'). The monotonicity assumption (A1) ensures that a negative (positive) correlation between profits and marginal profits translates into a positive (negative) correlation between marginal utility and marginal profits. In Section 3.1.1 below, it is discussed how the sign of $\rho^{i}$ depends on whether the uncertainty is about demand or costs, and if strategies are "quantities" or "prices". The restrictions (A1) imposes on uncertainty in demand/cost conditions are examined in Section 4.

Now it is immediately clear that to satisfy (2), the expected marginal profit must be of same sign as the correlation between $\pi^{i}$ and $\pi_{s^{i}}^{i}$, since it is the opposite of the correlation between $U_{\pi^{i}}^{i}$ and $\pi_{s^{i}}^{i}$. To see the implications in a non-strategic setting, consider a monopolist who has to set a single price or quantity under uncertainty. Let $s^{R N^{*}}$ be the riskneutral choice, defined by $E \pi_{s}\left(s^{R N^{*}}\right)=0$; the risk-averse choice is $s^{R A^{*}}$. There are two cases depending on the sign of the correlation between $\pi^{i}$ and $\pi_{s^{i}}^{i}$. First, if $\rho>0$ then it follows from (2) that $E \pi_{s}\left(s^{R A^{*}}\right)>0$. From concavity of the profit function $\pi_{s s}\left(s^{R N^{*}}\right)<0$, which

\footnotetext{
${ }^{4}$ For a discrete distribution of $\varepsilon$, the corresponding condition is that, for any two realisations $\varepsilon_{1}$ and $\varepsilon_{2}>\varepsilon_{1}, \pi$ is higher at $\varepsilon_{2} \forall \mathrm{s}^{\mathrm{i}}, \mathrm{s}^{\mathrm{j}} ; \operatorname{sign}\left(\rho^{\mathrm{i}}\right)$ follows from the relation between $\pi_{\mathrm{s}}$ at $\varepsilon_{1}$ and $\varepsilon_{2}$. Note that " $\pi$ is increasing in $\varepsilon^{\prime \prime}$ is in part a convention (it depends on whether the support of $\varepsilon$ is defined over positive or negative values).
} 
implies that $s^{R N^{*}}>s^{R A^{*}}$. Second, if $\rho<0$ then $E \pi_{s}\left(s^{R A^{*}}\right)<0$, and thus $s^{R N^{*}}<s^{R A^{*}}$. In words, if the correlation between profits and marginal profits is positive, then a quantity (price) setting risk-averse monopolist sets a lower quantity (price) than a risk-neutral counterpart. On the other hand, if the correlation is negative then the risk-averse monopolist sets a higher price or a higher quantity. This is essentially the result of Baron (1971). In the next section it will be shown how this carries over to different oligopoly settings.

\section{Competition among risk-averse firms}

\subsection{The effects of risk aversion on prices and quantities}

The first issue to examine is how firm i's risk aversion influences its strategy choice, holding firm j's risk aversion constant. To do so, define a new utility function, $\hat{U}^{i}\left[W^{i}\right]=G\left(U^{i}\left[W^{i}\right]\right)$, where $G$ is a positive, increasing, and concave function $\left(G_{U^{i}}>0\right.$ and $\left.G_{U^{i} U^{i}}<0\right) .{ }^{5}$ Hence, firm $\mathrm{i}$ is more risk-averse with utility function $\hat{U}^{i}$ than with $U^{i}$. The first-order condition with $\hat{U}^{i}$ is

$$
\hat{V}_{s^{i}}^{i}=E \hat{U}_{\pi^{i}}^{i} \pi_{s^{i}}^{i}=E G_{U^{i}} U_{\pi^{i}}^{i} \pi_{s^{i}}^{i}=0
$$

The corresponding best-response strategy, denoted $\hat{b}^{i}\left(s^{j}\right)$, will be compared to $b^{i}\left(s^{j}\right)$, for a given $s^{j}$. The question is if $\hat{b}^{i}$ is higher or lower than $b^{i}$. Note that if $G_{U^{i} U^{i}}=0$ (i.e., $\hat{U}^{i}$ and $U^{i}$ are equally risk-averse) then $b^{i}$ also satisfies (1'), since $G_{U^{i}}$ can be moved outside the expectations operator. The same is not true for $G_{U^{i} U^{i}}<0$.

Consider first the case where $\rho^{i}>0$. A realisation with low $\pi_{s^{i}}^{i}$ will carry a greater weight in (1') than in (1). The reason is that $\pi^{i}$ is also low, which implies a low $U^{i}$ and thereby a high $G_{U^{i}}\left(\right.$ from $\left.G_{U^{i} U^{i}}<0\right)$. Analogously, a realisation where $\pi_{s^{i}}^{i}$ is high will carry less weight in (1') than in (1). Taken together, this shows that $b^{i}$ would result in $E G_{U^{i}} U_{\pi^{i}}^{i} \pi_{s^{i}}^{i}<0$. Compared to $b^{i}, \hat{b}^{i}$ must have higher $\pi_{s^{i}}^{i}$ and $\pi^{i}$ in the low realisations

\footnotetext{
5 I am grateful for an anonymous referee's suggestion to use the formulation with the $G$-function, and for bringing my attention to Eeckhoudt and Gollier (1995).
} 
and, consequently, lower $\pi_{s^{i}}^{i}$ and $\pi^{i}$ in the high realisations. To see that this is accomplished by $\hat{b}^{i}<b^{i}$, note that in the lowest (highest) realisations $\pi_{s^{i}}^{i}<0\left(\pi_{s^{i}}^{i}>0\right)$ and that the profit function is concave, $\pi_{s^{i} s^{i}}^{i}<0$. Hence, to increase $\pi_{s^{i}}^{i}$ in the low realisations, and decrease it in the high realisations, it is necessary that $\hat{b}^{i}<b^{i}$.

Repeating the same steps for $\rho^{i}<0$ is straightforward. Here, a realisation where $\pi_{s^{i}}^{i}$ is low (high) will correspond to high (low) $\pi^{i}$, high (low) $U^{i}$, and small (large) weights, $G_{U^{i}}$. It follows that $b^{i}$ would give $E G_{U^{i}} U_{\pi^{i}}^{i} \pi_{s^{i}}^{i}>0$. To satisfy (1') calls for a strategy with lower (higher) $\pi_{s^{i}}^{i}$ in the lowest (highest) realisations. Again, from the concavity of the profit function it follows that $\hat{b}^{i}>b^{i}{ }^{6}$

Having derived the relation between the best-response strategies $\hat{b}^{i}\left(s^{j}\right)$ and $b^{i}\left(s^{j}\right)$, the relation between firm i's NE strategies follows directly, since firm j's best-response function is unchanged. For $\rho^{i}>0$, note that $\hat{b}^{i}\left(s^{j}\right)<b^{i}\left(s^{j}\right)$ holds for any $s^{j}$, in particular $s^{j^{*}}$ where $\hat{b}^{i}\left(s^{j^{*}}\right)<b^{i}\left(s^{j^{*}}\right)=s^{i^{*}}$. It is thus immediately clear that $\hat{s}^{i^{*}}<s^{i^{*}}$. Reversing the sign of $\rho^{i}$ yields $\hat{S}^{i^{*}}>s^{i^{*}}$. The above discussion is summarized in the key proposition.

Proposition 1: Let $\hat{U}^{i}$ be a more risk-averse utility function than $U^{i}$. With a positive correlation between profits and marginal profits $\left(\rho^{i}>0\right)$, the corresponding best-response functions satisfy $\hat{b}^{i}\left(s^{j}\right)<b^{i}\left(s^{j}\right)$, and the Nash equilibrium strategies $\hat{s}^{i^{*}}<s^{i^{*}}$. For $\rho^{i}<0$, $\hat{b}^{i}\left(s^{j}\right)>b^{i}\left(s^{j}\right)$ and $\hat{s}^{i^{*}}>s^{i^{*}}$.

Given the sign of $\rho^{i}$, the effect from changing firm i's risk aversion on firm j's NE strategy is dependent on the slope of the best-response functions. It is a standard exercise to show that if a change in firm i's first-order condition (holding firm j's first-order condition constant) results in a change from $s^{i^{*}}$ to $\hat{s}^{i^{*}}$ then the change from $s^{j^{*}}$ to $\hat{s}^{j^{*}}$ will be in the same (opposite) direction for $V_{s^{i} s^{j}}^{i}>0\left(V_{s^{i} s^{j}}^{i}<0\right)$. For instance, with $\rho^{i}>0$ it was shown that

\footnotetext{
${ }^{6}$ Note the analogy with the risk-neutral/risk-averse monopolist in the previous section: its price or quantity was higher (lower) when $\rho>0(\rho<0)$. In oligopoly, firm i is a "monopolist" on its residual demand curve. The counterpart to the monopolist's choice is firm i's best response function.
} 
$\hat{s}^{i^{*}}<s^{i^{*}}$, which with downward sloping best-response functions, $V_{s^{i} s^{j}}^{i}<0$, corresponds to $\hat{s}^{j^{*}}>s^{j^{*}}$. This is summarized in the following corollary to Proposition 1 .

Corollary 1: By making firm i more risk-averse its Nash equilibrium strategy change from $s^{i *}$ to $\hat{s}^{i^{*}}$ The change in firm $j^{\prime} s$ Nash equilibrium strategy will be in the same (opposite) direction as the change in firm i's Nash equilibrium strategy if $V_{s^{i} s^{j}}^{i}>0\left(V_{s^{i} s^{j}}^{i}<0\right)$.

Proposition 1 and Corollary 1 are illustrated in Figures 1A and 1B. The best-response functions corresponding to $U^{i}$ and $U^{j}$ are lines, those associated with the more risk-averse $\hat{U}^{i}$ are dashed. As shown in Figure 1A, the iso-profit function of firm $\mathrm{i}$ does not have an extreme point at any of the Nash equilibria (the iso-utility functions would).

\section{[FIGURES 1A AND 1B ABOUT HERE]}

In Appendix 1, I make a specific distributional assumption, namely that profits and marginal profits are approximately normally distributed. This allows the first-order condition (1) to be formulated in terms of the expected marginal profit, the Arrow-Pratt measure of global absolute risk aversion, and the correlation coefficient between profits and marginal profits.

\subsubsection{Illustration of the correlation between profits and marginal profits}

Can anything be said about the sign of $\rho^{i}$ ? As an illustration consider two familiar profit functions, based on linear demand for differentiated products and constant marginal cost,

$$
\begin{aligned}
& \pi^{i}\left(s^{i}, s^{j}, \varepsilon\right)=a s^{i}\left(b_{0}-b_{1} s^{i}-b_{2} s^{j}-c\right)+e \\
& \pi^{i}\left(s^{i}, s^{j}, \varepsilon\right)=a\left(s^{i}-c\right)\left(b_{0}-b_{1} s^{i}+b_{2} s^{j}\right)+e,
\end{aligned}
$$

with corresponding marginal profits

$$
\pi_{s^{i}}^{i}\left(s^{i}, s^{j}, \varepsilon\right)=a\left(b_{0}-2 b_{1} s^{i}-b_{2} s^{j}-c\right)
$$




$$
\pi_{s^{i}}^{i}\left(s^{i}, s^{j}, \mathcal{\varepsilon}\right)=a\left(b_{0}-b_{1}\left(2 s^{i}-c\right)+b_{2} s^{j}\right),
$$

where $\varepsilon$ refers to either $a, b_{0}, b_{1}, b_{2}$, c, or e. For positive values of $b_{1}$ and $b_{2}<b_{1}$, strategies are strategic substitutes (quantities) in (I1) and strategic complements (prices) in (I2). ${ }^{7}$ Now let $\varepsilon$ be uncertain with support $(\underline{\varepsilon}, \bar{\varepsilon})$ of positive values. The signs of $\rho^{i}$ in Table 1 are easily verified.

Table 1. Correlation between profit and marginal profit.

\begin{tabular}{lcccccc}
\hline & $a \in(\underline{\varepsilon}, \bar{\varepsilon})$ & $b_{0} \in(\underline{\varepsilon}, \bar{\varepsilon})$ & $b_{1} \in(\underline{\varepsilon}, \bar{\varepsilon})$ & $b_{2} \in(\underline{\varepsilon}, \bar{\varepsilon})$ & $c \in(\underline{\varepsilon}, \bar{\varepsilon})$ & $e \in(\underline{\varepsilon}, \bar{\varepsilon})$ \\
\hline $\begin{array}{l}\text { Strategic } \\
\text { Substitutes (I1) }\end{array}$ & $\rho^{i}{ }_{0}$ & $\rho^{i}>0$ & $\rho^{i}>0$ & $\rho^{i}>0$ & $\rho^{i}>0$ & $\rho^{i}=0$ \\
Strategic & $\rho^{i}>0$ & $\rho^{i}>0$ & $\rho^{i}>0$ & $\rho^{i}>0$ & $\rho^{i}<0$ & $\rho^{i}=0$ \\
Complements (I2) & $\rho^{>}$ & & & & & \\
\hline
\end{tabular}

With demand uncertainty $\left(\mathrm{b}_{0}, \mathrm{~b}_{1}, \mathrm{~b}_{2}\right), \rho^{i}>0$ for both strategic substitutes and complements. That $\rho^{i}>0$ also holds for marginal cost uncertainty (c) and strategic substitutes. In all these cases, realisations with high profits also have high marginal profits. The only case where $\rho^{i}<0$ is with marginal cost uncertainty and strategic complements. Additive uncertainty (e) results in zero correlation, and is therefore irrelevant in the choice of strategy. ${ }^{9}$ Finally, the reason for why multiplicative uncertainty (a) can result in either positive or negative correlation is that the sign of the marginal profit depends on the values of $s^{i}$ and $s^{j}$. Since multiplicative uncertainty does not conform with (A1) in general, the following treatment focuses on demand and cost uncertainty.

7 (I1) and (I2) are examples of polynomial profit functions that have a special property: linearity in the parameters. These will surface again in Section 3.3.2 in a discussion of more or less risky profit functions.

${ }^{8}$ Of course, if one would like to calculate the Nash equilibrium strategies it is necessary to impose restrictions on the fixed parameters, and the support for the uncertain parameter. As this is only an illustration of the correlation between profits and marginal profits it is simply assumed that at these implied restrictions are satisfied.

${ }^{9}$ Note that this also implies that uncertainty about the level of fixed costs is ignored by the risk-averse firm (it will, however, reduce its expected utility), since one could just define the profits as operating profits net of fixed costs. 


\subsubsection{Intuition and effects on expected price-cost margins}

Proposition 1 and Table 1 suggest a simple intuition for the risk-averse firm's strategy choice. The risk-averse firm puts relatively greater weight on realisations where profits are low. Under cost uncertainty, the sign of the correlation between profits and marginal profits, is dependent on whether firms set quantities or prices, and best-response quantities are low, and best-response prices are high. The intuition is that a high price, or a low quantity, protects the firm by restricting output in the high cost states. Under demand uncertainty (positive correlation between profit and marginal profit), low quantities and low prices are optimal in the low demand states. For this reason, more risk aversion shifts the best-response function downward.

Proposition 1 provides an immediate implication of an increase in firm i's risk aversion on its expected price-cost margin. With cost uncertainty, the price of its product in the NE will increase - irrespective of the nature of competition. This implies that its expected pricecost margin is increasing in its risk aversion. The same prediction can not be drawn for demand uncertainty, since its price in NE is lower if firms are competing in prices, but higher if competition is in quantities.

Corollary 1 can be used to determine if firm j's expected price-cost margin is also unambiguously higher under cost uncertainty. With price competition, firm j's NE price is higher, and so is its expected price-cost margin. With quantity competition, on the other hand, the issue is more involved as firm j's NE quantity is higher, which tends to counteract the effect firm i's lower NE quantity has on the price of firm j's product. A priori it is not clear which effect that dominates, and I am not aware of any general result that extends to differentiated products. However, reference to a simple argument provides the intuition for why firm j's price in NE should increase. Note that how much firm j's NE quantity increases depends on the degree of product differentiation: the greatest increase is when the two firms' products are homogenous; the smallest increases are when demands are almost independent. For homogenous products, firm j's NE quantity will increase by less than the decrease in firm i's NE quantity (see e.g., Dixit, 1986). It follows that the price of firm j's (and firm i's) product 
in NE is higher, and so is firm j's expected price-cost margin. At the other end, with completely independent demands, there is no price effect. Although this is not a rigorous proof that the expected price-cost margin of the rival rises when there is cost uncertainty, it nevertheless strongly suggests that an increase in a competitor's risk-aversion tends to have this effect. ${ }^{10}$

So far, only a change in one firm's risk aversion has been considered. Can anything be said when both firms' risk aversion is increased, in the presence of cost uncertainty? That the answer is yes follows from the same analysis as in the preceding two paragraphs. Without repeating the argument: under cost uncertainty the expected price-cost margin for each firm is higher the more risk-averse firms are. Predictions for demand uncertainty will hinge on the nature of competition.

\subsection{Fixed costs}

The level of fixed costs is irrelevant for the choice of strategy in a one-shot game with riskneutral players. This, in general, does not hold for risk-averse players. In this section, I therefore examine how best response functions depend on fixed costs.

It seems uncontroversial to assume that the absolute risk aversion, $r^{i}\left(w^{i}\right) \equiv-U_{w^{i} w^{i}}^{i} / U_{w^{i}}^{i}$, is decreasing in $w^{i}$ or, equivalently, increasing in $f^{i}$. For utility functions with decreasing absolute risk aversion (DARA), an increase in fixed costs from $f^{i}$ to $\hat{f}^{i}$ makes firm i more risk-averse. How does this effect its best-response function? The answer follows directly from Proposition 1, which referred to the general case of a change in risk aversion, since, under DARA, an increase in fixed costs is equivalent to an increase in risk aversion. Hence, no new proof is needed to state the second proposition.

\footnotetext{
${ }^{10}$ In the discussion it was tacitly assumed that marginal costs were constant, but uncertain for one firm. A full proof of the effects on expected price-cost margins would need to incorporate cases with increasing, or decreasing marginal costs. In the special case where marginal costs are constant, and firm $j$ 's inverse demand is of the form $p^{j}=b_{0}-b_{1} q^{j}-b_{2} q^{i}$ with $b_{1} \geq_{2}>0$, it can be verified that its expected price-cost margin increases.
} 
Proposition 2: Let firm i's utility function have decreasing absolute risk aversion, such that increasing the fixed costs from $f^{i}$ to $\hat{f}^{i}$ makes the firm more risk-averse. With a positive correlation between profits and marginal profits $\left(\rho^{i}>0\right)$, its best-response functions for the two levels of fixed costs satisfy $\hat{b}^{i}\left(s^{j}\right)<b^{i}\left(s^{j}\right)$, and the Nash equilibrium strategies $\hat{s}^{i^{*}}<s^{i^{*}}$. For $\rho^{i}<0, \hat{b}^{i}\left(s^{j}\right)>b^{i}\left(s^{j}\right)$ and $\hat{s}^{i^{*}}>s^{i^{*}}$.

For $\rho^{i}>0$, an increase in firm i's fixed cost leads to a lower best-response strategy. The intuition is simple: higher fixed costs make the bad realisations even worse for a risk-averse firm. To reduce the impact of these, the risk-averse firm lowers its quantity or price, to be better adjusted in the bad realisations. For $\rho^{i}<0$, firm $i$ will increase its price to limit the exposure to states with high marginal costs. The extent to which an increase in firm i's fixed costs increase its, and firm j's, expected price-cost margins follows from Section 3.1.2.

Proposition 2 corresponds to results in the early works of Baron (1970), Sandmo (1971) and Leland (1972) for perfectly competitive and monopoly environments. It is straightforward to extend Proposition 2 to cover two forms of strategic investment models.

\subsubsection{Strategic sunk cost investments}

Proposition 2 has direct implications for the class of strategic investment models which involves an initial fixed (sunk) outlay; see Tirole (1988) for various applications. The intuition is that the investment reduces the firm's wealth, and thereby changes its risk aversion in the future.

As an illustration, in the quintessential strategic investment model of Dixit (1980), it is assumed that an incumbent firm, faced with a potential entrant, can make a sunk investment in a cost reducing technology. By pursuing the investment it can commit to an output expansion in a second stage. Let the competition be in quantities, $V_{s^{i} s^{j}}^{i}<0$, and depart from the standard set-up by introducing demand uncertainty in second stage $\left(\rho^{i}>0\right)$.

The only effect that the investment has for a risk-neutral firm is to increase the bestresponse quantity by lowering cost of production. To a risk-averse incumbent there is a counteracting effect, since the investment also reduces its wealth level and thereby increases 
its risk aversion. In Proposition 2 it was shown that this reduces its second stage best-response strategy. Hence, the cost reducing investment is less attractive to a quantity setting risk-averse incumbent. On the other hand, if competition is in prices, $V_{s^{i} s^{j}}^{i}>0$, the two effects work in the same direction: lower costs of production tend to reduce its price and demand uncertainty reinforces this effect. Therefore the price setting risk-averse incumbent can achieve the same strategic effect by a smaller investment.

Finally, note that uncertainty regarding marginal costs makes the strategic investment less effective for both quantity and price competition. The reason is that higher fixed costs tend to lower quantities, or raise prices, and thereby counteract the cost reduction achieved by the investment.

\subsubsection{Relevance of accumulated profits}

Just as fixed costs influence the risk-averse best-response function so do past profits. To illustrate, consider a two period model where firm $i$ is risk-averse (with DARA) and firm $j$ is risk-neutral. Further, there are no fixed costs and the only uncertainty arise in second period, such that the objective functions are $E U^{i}\left[w^{i}+\pi^{i 1}+\pi^{i 2}\right]$ and $\pi^{j 1}+E \pi^{j 2} \cdot{ }^{11}$

At $\mathrm{t}=2$, the risk-neutral firm $\mathrm{j}$ maximizes expected profits, irrespective of its period one profits. This, however, is not the case with the risk-averse firm. Its best-response function depends on the first period profit, $b^{i 2}\left(s^{j 2}, \pi^{i 1}\right)$. The only additional strategic element in this setting is that at $\mathrm{t}=1$, the risk-neutral firm needs to take into account how its choice of $s^{j 1}$ influences $\pi^{i 1}$, as that will determine the risk-averse firm's behaviour at $\mathrm{t}=2$.

$$
\begin{aligned}
& \text { At } \mathrm{t}=1 \text {, firm j's first-order condition is } \\
& \pi_{s^{j 1}}^{j 1}+E \pi_{s^{i 2}}^{j 2} b_{\pi^{i 1}}^{i 2} \pi_{s^{j 1}}^{i 1}=0,
\end{aligned}
$$

where the second term is the strategic effect. (Note that its first-order condition at $t=2$ is $E \pi_{s^{j 2}}^{j 2}=0$, which is why there is no indirect effect on firm j's own best-response - the

\footnotetext{
11 It is possible to generalise the framework to two risk-averse firms. A further extension is to introduce uncertainty in both periods. The additional complication is that one needs to model the correlation of realisations across periods (for instance, whether demand shocks are positively or negatively autocorrelated).
} 
envelope property.) ${ }^{12}$ Under the assumption that the game firms play is symmetric, in the sense that $\operatorname{sign}\left(\pi_{s^{i 2}}^{j 2}\right)=\operatorname{sign}\left(\pi_{s^{j 1}}^{i 1}\right)$, the sign of the strategic effect depends only on the sign of $b_{\pi^{i 1}}^{i 2}$. This is where Proposition 2 comes into play - period one profits is just the opposite of fixed costs. There will be two cases depending on $\operatorname{sign}\left(\rho^{i}\right)$.

For $\rho^{i}>0$, the risk-averse firm's best-response strategy is increasing in its period one profit, $b_{\pi^{i 1}}^{i 2}>0$. To satisfy (3), firm $\mathrm{j}$ 's marginal profit at $\mathrm{t}=1$ must then be negative. From concavity of the profit function, addition of the strategic effect gives a higher best-response strategy at $\mathrm{t}=1$ than that defined by $\pi_{s^{j 1}}^{j 1}=0$. The intuition behind the strategic effect is as follows for quantity, and price setting firms. The quantity setting firm $\mathrm{j}$ will be more aggressive, in the sense that its best response-function quantity is higher, to reduce the riskaverse firm's profit. The motive is that this makes firm i more risk-averse, which leads to a lower best-response quantity at $\mathrm{t}=2$. Conversely, the price setting firm $\mathrm{j}$ prices less aggressively, in order to meet a less risk-averse firm. In a price competition setting where $\rho^{i}<0$ the situation is reversed. Firm $\mathrm{j}$ prices low in the first period to reduce the risk-averse firm's profit. This induces the risk-averse firm to set a higher price at $\mathrm{t}=2 .{ }^{13}$

\subsection{Firm specific risk and market risk}

For empirical testing it is desirable to have predictions on how an increase in risk influences the risk-averse best-response function. To address this question the notion of "an increase in risk" must be defined. Let $F_{0}(x)$ be a cumulative density function (cdf) of a random variable

\footnotetext{
12 There is no strategic effect in firm i's first-order condition at $t=1$, since firm $\mathrm{j}$ always maximizes expected profits in the second period. Further, it follows from the envelope property that there is no indirect effect from firm i's first period strategy choice on its own behaviour at $t=2$. In fact, firm i will behave as it was riskneutral at $\mathrm{t}=1$, since there is no uncertainty at this stage.

13 The insight that past profits matter for future competition is related to the model by Glazer (1994), where indebted firms compete in quantities in two periods. Limited liability of equity holders make them risk seeking, and more so the more outstanding debt there is. First period profits will determine the net debt in the second period. With quantity competition, it is shown that firms will reduce their quantities to give the competitor higher profits, which makes second period competition softer. Risk aversion has the opposite effect: the risk-neutral firm expands output to reduce the profits of the rival, and thereby increase its second period risk aversion to soften competition.
} 
$\mathrm{x}$, with support on the bounded interval $(\underline{x}, \bar{x})$, which will be compared to a "more risky" cdf, $F_{1}(x)$. If $F_{0}$ and $F_{1}$ have the same mean then $F_{0}$ second-order stochastically dominates (SSD) $F_{1}$ if $\int_{\underline{x}}^{t} F_{0}(x) d x \leq \int_{\underline{x}}^{t} F_{1}(x) d x$ for $\forall t \in(\underline{x}, \bar{x})$. I will examine two ways in which firm i's payoff is more risky in the SSD sense. First, by adding a background risk, which is independent of its operating profit, to its payoff. Second, by letting the operating profit become more risky.

\subsubsection{Background risk}

Consider introducing a firm specific background risk, denoted $\hat{z}^{i}$, to make firm i's payoff $\hat{W}^{i}=w^{i}+\pi^{i}+\hat{z}^{i}$, rather than $W^{i}=w^{i}+\pi^{i}$. Let $\pi^{i}$ and $\hat{z}^{i}$ be independent, and assume further that $\hat{z}^{i}$ is an "unfair" risk in the sense that $E \hat{z}^{i} \leq 0$ (if $E \hat{z}^{i}=0$ then $w^{i}+\pi^{i} \mathrm{SSD}$ $\left.w^{i}+\pi^{i}+\hat{z}^{i}\right)$. This background risk can be interpreted as uncertain outcomes in other industries where firm i operates, but which are unrelated to those in the industry where it competes with firm j. Alternatively, it can be interpreted as uncertainty about fixed costs, which is orthogonal to the uncertain operating profit. To analyse the consequences for risk taking behaviour, construct a derived utility function by $\hat{U}^{i}\left[w^{i}\right]=E U^{i}\left[w^{i}+\hat{z}^{i}\right]$.

Gollier and Pratt (1996) define risk-vulnerability such as for any unfair risk $\left(E \hat{z}^{i} \leq 0\right)$ : $r^{i}\left(w^{i}\right) \equiv-U_{w^{i} w^{i}}^{i}\left[w^{i}\right] / U_{w^{i}}^{i}\left[w^{i}\right] \leq-E U_{w^{i} w^{i}}^{i}\left[w^{i}+\hat{z}^{i}\right] / E U_{w^{i}}^{i}\left[w^{i}+\hat{z}^{i}\right] \quad$ for $\quad \forall w^{i} . \quad \mathrm{A} \quad$ sufficient condition for this property is that $r^{i}$ is positive, decreasing and convex. ${ }^{14}$ They show that if firm $\mathrm{i}$ is risk-vulnerable, it is more averse to a risk in $\pi^{i}$ with utility $\hat{U}^{i}$ (where the background risk is present) than with $U^{i} .{ }^{15}$ Kimball (1993) provides an alternative restriction on the utility function $U^{i}$ to ensure that $\hat{U}^{i}$ is more risk-averse, namely that $U^{i}$ displays standard risk aversion, which is equivalent to DARA and decreasing absolute prudence, DAP $\left(-U_{w^{i} w^{i} w^{i}}^{i} / U_{w^{i} w^{i}}^{i}\right.$ is positive and decreasing in $\left.w^{i}\right)$. By abusing notation, let firm i's best

\footnotetext{
14 This condition is satisfied for the class of utility functions with hyperbolic absolute risk aversion, HARA, which encompasses most common utility functions.

15 The comparison was between when background risk is present and when it is not. Eeckhoudt et al. (1996) consider the more general case where one background risk SSD another. They show that restrictions similar to risk-vulnerability assure that behaviour is more risk-averse when the background risk is more risky.
} 
response function be $b^{i}\left(s^{j}\right)$ when no background risk is present and $\hat{b}^{i}\left(s^{j}\right)$ when it is. The relation between the two best-response functions follows from Proposition 1.

In the previous paragraph, the background risk was firm specific. The same argument can be repeated for "economy-wide" background risk, $\hat{z}$. This is a risk that affects both firms' payoff but is unrelated to the market where they compete. Adding this background risk to each of the two risk-averse firms' payoff will have unambiguous effects on their best response functions whenever the utility functions are risk-vulnerable/satisfy standard risk aversion. However, whether the effect on the NE strategies is also clear-cut depends on the slopes of the best response functions. It can easily be verified that with strategic complements the effect on the NE strategies is unambiguous, whereas it is not in case of strategic substitutes. ${ }^{16}$

\subsubsection{Market risk}

I conclude the examination of changes in risk by a treatment of the analytically more complex situation where firm i's profit function becomes more risky. This is referred to as an increase in market risk, and could be thought of as more uncertain demand, or cost conditions. There are, unfortunately, few general predictions that can be made only from the assumption that $F_{0}\left(\pi^{i}\right) \operatorname{SSD} F_{1}\left(\pi^{i}\right)$. To understand why, to the profit function described by $F_{0}\left(\pi^{i}\right)$, $\pi^{i}\left(s^{i}, s^{j}, \varepsilon\right)$, add a disturbance, $z$, to form $\pi^{i}\left(s^{i}, s^{j}, \varepsilon^{\prime}\right)$, where $\varepsilon^{\prime}=\varepsilon+z, E z=0$, and $E z \mid \varepsilon=0$. Denote the new distribution $F_{1}\left(\pi^{i}\right)$. Firm i's first-order condition under the two distributions are

$$
\begin{aligned}
& E U_{\pi^{i}}^{i}\left[w^{i}+\pi^{i}\left(s^{i}, s^{j}, \mathcal{\varepsilon}\right)\right] \pi_{s^{i}}^{i}\left(s^{i}, s^{j}, \varepsilon\right)=0 \\
& E U_{\pi^{i}}^{i}\left[w^{i}+\pi^{i}\left(s^{i}, s^{j}, \varepsilon+z\right)\right] \pi_{s^{i}}^{i}\left(s^{i}, s^{j}, \mathcal{E}+z\right)=0 .
\end{aligned}
$$

\footnotetext{
${ }^{16}$ This parallels the effect of changing both firms' marginal costs in the same direction. For both firm i and firm $\mathrm{j}$, higher marginal cost shifts its best response prices (quantities) up (down). But whereas the other firm's best response to a higher price by the rival is to increase its price, its best response to a lower quantity by the rival is to increase its quantity. In the price setting case the two effects work in the same direction, but with quantity setting firms the total effect on the NE strategies depends on the relative strengths of two opposing effects. E.g., Dixit (1986) provides conditions for unambiguous effects in a risk-neutral market.
} 
There are several problems involved in comparing the best-response functions defined by (4) and (5), which I denote $b^{i}\left(s^{j}\right)$ and $\hat{b}^{i}\left(s^{j}\right)$, respectively. A minor problem is that for many profit functions, monotonicity of $\pi^{i}$ and $\pi_{s^{i}}^{i}$ in $\varepsilon$ (as required by (A1)) is no guarantee that $E \pi^{i}\left(s^{i}, s^{j}, \varepsilon\right)=E \pi^{i}\left(s^{i}, s^{j}, \varepsilon+z\right)$, such it can't be asserted that $F_{0}$ SSD $F_{1} .{ }^{17}$ When SSD does not follow from $\varepsilon^{\prime}=\varepsilon+z$, one has to define a joint function, $\varepsilon^{\prime}=f(\varepsilon, z)$, such that it does. The conjecture is that this approach is unlikely to prove tractable. The reason is a fundamental problem, namely that $F_{0}\left(\pi^{i}\right) \operatorname{SSD} F_{1}\left(\pi^{i}\right)$ does not provide sufficient information on the joint distribution of marginal profits and marginal utilities. ${ }^{18}$ Hence, in general it is difficult to compare $b^{i}\left(s^{j}\right)$ and $\hat{b}^{i}\left(s^{j}\right)$.

To show that SSD can be sufficient to obtain predictions on the best response functions, I examine the two profit functions (I1) and (I2) from Section 3.1.1. To simplify the proofs (given in Appendix 2), I use the simplest conceivable setting, where $\varepsilon^{\prime}=\varepsilon+z, \mathrm{E} z=0, \mathrm{E} z \mid \varepsilon=0, z$ has only two outcomes, and $\varepsilon$ and $\varepsilon^{\prime}$ refers to one of the parameters $b_{0}, b_{1}, b_{2}$, or c. Hence, the first-order conditions are given by (4) and (5). It is easy to verify that $F_{0}\left(\pi^{i}\right) \operatorname{SSD} F_{1}\left(\pi^{i}\right)$.

In the most bare bones case there is no uncertainty about $\varepsilon$ (i.e., $F_{0}\left(\pi^{i}\right)$ is degenerate). Let the best-response functions, conditional on $\varepsilon$, be denoted $b^{i}\left(s^{j} \mid \varepsilon\right)$ and $\hat{b}^{i}\left(s^{j} \mid \varepsilon\right)$. As noted above, a priori it is not clear how two profit functions with the same mean but different distributions will translate into best response functions. In Appendix 2, I show that $b^{i}\left(s^{j} \mid \varepsilon\right)>\hat{b}^{i}\left(s^{j} \mid \varepsilon\right)$ when $\rho^{i}>0 .{ }^{19}$ In words, the best response strategies for the risky distribution are lower when there is a positive correlation between profits and marginal

${ }^{17}$ An example is the constant elasticity inverse demand function for homogenous products, $p=\left(q^{i}+q^{j}\right)^{(-\varepsilon)}$, where $\varepsilon$ is uncertain. Profit and marginal profits are monotone in $\varepsilon$ (i.e, it satisfy (A1)), but $\pi_{\varepsilon}$ is not constant. 18 One is easily led to think that some version of Jensen's inequality (i.e., for a concave utility function $\mathrm{U}[\mathrm{E} \pi]>\mathrm{EU}[\pi]$ ) can be applied to this problem. However, even though $\mathrm{U}_{\pi}[\pi]$ is (under reasonable assumptions) a convex transformation, it is not multiplied by $\pi$ but $\pi_{\text {s. }}$.

19 Note that this does not follow from Proposition 1, where the distribution of uncertainty was held constant and the degree of risk aversion was changed. This is the opposite: the degree of risk aversion is held constant and the distribution of uncertainty is changed. Neither is this an application of background risk as in Section 3.3.1, for reasons spelled out in Appendix 2. 
profits-conditional on the value of $\varepsilon$. The inequality is reversed for $\rho^{i}<0$. In this special case, where $F_{0}\left(\pi^{i}\right)$ is degenerate, it is possible to relate SSD to best-response functions.

The next part of Appendix 2 shows that it is also possible to derive a relation between $b^{i}\left(s^{j}\right)$ and $\hat{b}^{i}\left(s^{j}\right)$, for the special case where $\varepsilon$ also has two outcomes. Similar to the degenerate case, $b^{i}\left(s^{j}\right)>\hat{b}^{i}\left(s^{j}\right)$ when $\rho^{i}>0$; again with reversed inequality for $\rho^{i}<0.20$

While it is possible to extend these examples beyond the $1 \times 2$, and $2 \times 2$ space (simply by adding more $\varepsilon$ 's), a completely general treatment of SSD in oligopoly is likely to involve some strong assumptions on the profit and marginal profit functions and/or the distribution of uncertainty. ${ }^{21}$ Nevertheless, the analysis in this section suggests that for the rather flexible class of profit functions that (I1) and (I2) represents, it is possible to say that an increase in risk translates to best response functions in a way that confirms the basic intuition.

\section{Discussion}

In the paper assumptions were made to simplify the exposition and show the key effects of risk aversion in oligopoly. It is now appropriate to discuss the robustness of the results, in particular since an objective is to derive testable implications.

In the framework, only mild restrictions were made on utility functions (such as DARA in Section 3.2 and, in addition, DAP in Section 3.3.1), and no restrictions on the distribution of the uncertainty other than a bounded support consistent with a unique stable NE. On the other hand, the assumption (A1) regarding how uncertainty enters in the profit function can be more restrictive.

The main objection is that it is unclear which profit functions and forms of uncertainty that comply with (A1), which, put simply, says that there is a strict ranking between profits

\footnotetext{
${ }^{20}$ This does not follow from the previous paragraph, since the distributions of marginal profits and marginal utilities are different.

21 A specific example with strategic substitutes and demand uncertainty has been previously analysed by Tessiotore (1994).
} 
and marginal profits in the realisation of uncertainty for all strategy choices. ${ }^{22}$ In fact, already in the simplest examples ((I1) and (I2) in Section 3.1.1) there were two types of uncertainty that did not satisfy (A1). First, additive uncertainty in the operating profits gives no relation between profits and marginal profits. It is therefore irrelevant in the strategy choice. Second, by multiplying operating profit with an uncertain factor, but leaving demand and cost conditions unchanged, made the ranking dependent on firms' strategies. While this case is interesting and can be dealt with, it can not be handled within the framework provided by (A1). In the exposition, I have referred to uncertainty that relates to either demand, or cost conditions. The question is then if the results are robust to different forms of demand and cost uncertainty. It is argued that, for reasonable parameterisations, they are.

It is most important to verify that conclusions hold for cost uncertainty, where it was argued that the predictions for (relatively) tangible variables (e.g., prices, quantities and expected price-cost margins) were independent of factors such as whether firms are competing in "quantities" or "prices". The intuition was that the more risk-averse firm, faced with marginal cost uncertainty, has lower best response quantities and higher best response prices (which implies low quantities), as to limit exposure to realisations where marginal costs are high. To examine if the intuition is valid, let the total variable costs be $C^{i}\left(q^{i}, \varepsilon^{C}\right)$ and the marginal costs $C_{q^{i}}^{i}\left(q^{i}, \varepsilon^{C}\right)$, where $q^{i}$ is the quantity (in price competition it is $\left.q^{i}=D^{i}\left(p^{i}, p^{j}\right)\right)$. What (A1) requires is that, conditional on $q^{i}$, realisations of $\varepsilon^{C}$ with high total variable costs also have high marginal costs. Formally, $C_{\varepsilon^{c}}^{i}\left(q^{i}, \varepsilon^{C}\right)$ and $C_{q^{i} \varepsilon^{c}}^{i}\left(q^{i}, \varepsilon^{C}\right)$ should have the same sign for all $q^{i}$. Note first that (A1) holds trivially when $\varepsilon^{C}$ refers to the

22 That (A1) holds globally is stronger than needed; it is sufficient that it holds over the relevant set of strategies. The same is true for the assumption on global concavity of the profit function. 
level of an uncertain constant marginal cost, $C^{i}\left(q^{i}, \varepsilon^{C}\right)=\varepsilon^{C} q^{i} .{ }^{23}$ More generally, for (A1) to fail, it is necessary that the uncertainty amounts to a rotation of the marginal cost curve (i.e., marginal costs must be higher for some quantities but lower for others). ${ }^{24}$ These appear to be contrived cases, and I therefore conclude that (A1) holds for any common form of cost uncertainty.

Consider next the case of demand uncertainty, where risk aversion did not provide definite predictions (i.e., independent of unobservables) on measurable variables. Here the intuition was that a more risk-averse firm's best response quantity is lower and that its best response price is also lower, since low prices, or low quantities, perform well in states where demand is low. To analyse this more intricate case, write firm i's inverse demand and marginal demand as $D^{i}\left(q^{i}, q^{j}, \varepsilon^{D}\right)$ and $D_{q^{i}}^{i}\left(q^{i}, q^{j}, \varepsilon^{D}\right)$, respectively. Under (A1), $D_{\varepsilon^{D}}^{i}\left(q^{i}, q^{j}, \varepsilon^{D}\right)$ and $D_{q^{i} \varepsilon^{D}}^{i}\left(q^{i}, q^{j}, \varepsilon^{D}\right)$ are assumed to have the same sign. With demand uncertainty, it is more difficult to rule out violations of (A1). One example is $D^{i}\left(q^{i}, q^{j}, \varepsilon^{D}\right)=b_{0}-\varepsilon^{D} q^{i}+f\left(\varepsilon^{D}\right) q^{j}$, where $f\left(\varepsilon^{D}\right)>0$ and $f_{\varepsilon^{D}}\left(\varepsilon^{D}\right)>0$, which corresponds to a situation where firm $\mathrm{i}$ is uncertain about the degree of product differentiation. On the other hand, (A1) holds when $\varepsilon^{D}$ enters in only once in the demand function. It is difficult to judge whether uncertainty which, in effect, rotates demand is common in practice; the prior is that (A1) remains the norm. However, the observation that the exact form of demand uncertainty may influence outcomes merely reinforces the problems for empirical testing,

${ }^{23}$ Equally straightforward is the case of a marginal cost function of the form $C^{i}\left(q^{i}, \varepsilon^{c}\right)=a q^{i}+b\left(q^{i}\right)^{k}$ for $k \neq 1$ where $\varepsilon^{\mathrm{c}}$ refers to one of a or $\mathrm{b}$. Note, however, introducing increasing marginal costs in a model with price competition will raise issues regarding the very existence of a pure strategy NE. Wambach (1999) has recently shown that price competition with homogenous products and constant, but uncertain, marginal costs has a NE in pure strategies, with positive expected price cost margins when firms are risk-averse (without risk aversion, prices fall to expected marginal costs-the Bertrand paradox). This seems to suggest that with increasing marginal costs, a pure strategy NE can exist when firms are risk-averse where it would not otherwise.

${ }^{24}$ One such example is a marginal cost function $b+\varepsilon^{c}+\left(1 / \varepsilon^{c}\right) q^{i}$ for $b>0$. This rotation violates (A1). One might take this a step further by applying duality theory and ask what the underlying production function looks like, and which joint distribution of uncertain factor prices (one uncertain factor price can not rotate the marginal cost) that give rise to the uncertainty in $\varepsilon^{c}$. These questions are interesting, but are beyond the scope of the present work. 
since the behaviour of risk-averse firms, even when (A1) holds, depends on whether they are assumed to set prices or quantities.

Finally, the two paragraphs above relate to another restriction in the model, namely that there is uncertainty about demand or costs. In many markets, however, there can be uncertainty about both, and one would therefore need to examine their joint distribution. To analyse this in detail is beyond the scope of the present paper. One remark can nevertheless be made on the applicability of Proposition 1. Assume that the distributions are independent, and each satisfies (A1) conditional on the realisation of the other. For quantity competition the two sources work in the same direction ( $\rho^{i}>0$ from both the demand and the cost source), whereas with price competition it is necessary to examine the relative strength of two opposing effects ( $\rho^{i}>0$ from demand and $\rho^{i}<0$ from costs).

\section{Empirical implications and tests of the predictions}

The main finding - for empirical testing - was that only in the case of marginal cost uncertainty are the predictions on observable variables (prices, quantities, expected price-cost margins) independent of whether firms compete in "prices" or "quantities". For marginal cost uncertainty, competition between risk-averse firms is softer when firms are more risk-averse; have higher fixed costs; have lower accumulated profits; and the more background risk they face. In a more specific setting, with linear demand for differentiated products, more uncertain cost conditions (in the second order stochastic dominance sense) reduce the intensity of competition. For demand uncertainty, on the other hand, risk-aversion makes competition in prices fiercer, but softens quantity competition, i.e. empirical predictions can only be made conditional on the nature of competition. The issue is if the derived predictions are sufficiently sharp to have empirical content. It is argued that they are, and I will conclude by outlining some strategies to test the hypothesis that risk aversion influences the intensity of competition. 
The above paragraph suggests that empirical tests should be directed towards markets with significant cost uncertainty. To identify those, a simple measure can be based on the ratio of the standard deviation to the mean for the most important input price. Alternatively, the amount of cost uncertainty should be inversely related to the possibility to predict the input price by time series methods (for example, in its most basic form, $1 / \mathrm{R}^{2}$ from an $\mathrm{AR}(1)$ regression on the input price). Importantly, these two measures can be compared across industries and markets, as well as over time periods. To find corresponding measures that reflect demand uncertainty poses a greater challenge. In an inter-industry comparison, one is probably forced to treat the industries where there is demand uncertainty, but little cost uncertainty, as a control group for which theory gives no guidance. However, in an intraindustry study, with either geographical and/or time series variation, it might be possible to identify demand uncertainty by some intrinsically non-predictable variable such as weather conditions. But again, the predictions are conditional on the nature of competition in so far it can not be estimated.

To search for broad evidence of strategic effects of risk aversion it is useful to begin with inter-industry (Structure-Conduct-Performance) studies, despite their well-known limitations. First, some studies have tested if some measure of risk (often the standard deviation of historical profits) is correlated with profitability at the firm and industry level. In Schmalensee's (1989 p.973) survey, five studies report a positive, three an insignificant, and two a negative correlation. ${ }^{25}$ To my knowledge, no study has attempted to split the sample according to the nature of uncertainty as suggested here. Second, a common finding in cross industry studies is that profitability is positively correlated with some measure of capital requirements in the industry, Schmalensee (1989 p.978). This is often explained by the presence of entry barriers, as large capital requirement is a proxy for large minimum efficient scale. Risk aversion provides an alternative explanation - more fixed costs increase firms' risk aversion and thereby softens competition (except in case of demand uncertainty and price

\footnotetext{
25 The studies include firms that are large and, presumably, diversified with operations in several industries (some study only firms in the Fortune 500). Such samples are clearly not ideal to trace effects of risk aversion on oligopolistic interaction.
} 
competition). A test of this is to interact the fixed costs with one of the proposed measures of cost uncertainty; a positive coefficient supports the risk aversion alternative.

By shifting attention to intra-industry studies, it is possible to more directly test the hypothesis that risk aversion is a determinant of competition intensity. A large number of studies employ time series variation in costs and demand to identify a firm's (or a group of firms') behaviour by estimating a "conduct parameter", $\theta$ (see Bresnahan, 1989, for a discussion and evidence from early studies, and Genesove and Mullin, 1998, for a particularly instructive recent study). Under the hypothesis that risk aversion is important for firms' behaviour, $\theta$ should vary with the degree of uncertainty as well as with the amount of fixed costs. To be able to identify this, the sample must include periods where the underlying cost/demand conditions are unusually uncertain, or an exogenous change in fixed costs. If changes in the intensity of competition can be detected in such periods then this is indicative of risk-averse behaviour. ${ }^{26}$ I am not aware of any study that has parameterised $\theta$ to be a function of the degree of uncertainty or fixed costs. Furthermore, by taking $\theta$ literally (i.e., not merely as a measure of the degree of market power), the estimated value of $\theta$ provides information about the nature of competition. This suggests that one can perform joint tests of $\theta$ and the type of uncertainty. For example, if the estimated $\theta$ is in the range where implied behaviour is Cournot competition with homogenous products, then periods with more demand uncertainty should be less competitive. Another line of single industry studies relates price levels in different geographical markets to the intensity of competition, but without estimating

\footnotetext{
${ }^{26}$ There are alternative explanations to such finding, however. In a model of implicit collusion but imperfect monitoring (e.g., Green and Porter, 1984) the NE may change with the degree of uncertainty. Furthermore, if firms endogenously choose whether to use price or quantity as the strategic variable it is possible that the degree of uncertainty change the nature of competition (see e.g., Klemperer and Meyer, 1986, 1989, and Weitzman, 1981). Nevertheless, there is no reason for why an exogenous change in fixed costs would change the behaviour of risk-neutral firms.
} 
any $\theta$. This method can only be used to test the predictions outlined here insofar as the degree of uncertainty differs across markets. ${ }^{27}$

In the paper it was also shown that strategic investments have additional effects when they increase fixed costs. Take the most straightforward case, where incumbent firms faced by the threat of entry can commit to unfavourable post-entry conditions by investing in capacity to reduce their marginal costs. Under the hypothesis that firms are risk-averse, such capacity investments may prove less effective since increased fixed costs also raise risk aversion and thus change post-entry competition. A prediction is that ceteris paribus uncertain cost conditions (measured by factor prices) makes it less likely that firms make strategic investments in capacity. The empirical evidence on strategic use of capacity is scarce, despite the strategy's intuitive appeal. For example, in Lieberman's (1987) seminal study of capacity investments in 38 chemical industries (where strategic investments should be effective if anywhere), only in a handful of cases did firms appear to use capacity in order to deter entry. The limited evidence can be explained by risk aversion, but may also be attributed to several other factors (informational asymmetries, co-ordination failures among incumbents, freeriding problems).

It was shown that the intensity of competition is partly determined by firms' accumulated profits - firms being less willing to accept risks when their wealth levels are low. One interpretation is that firms' wealth levels are low in when demand has been low for some time. By identifying such periods with recessions suggests that risk aversion will leave a trace in the intensity of competition over the business cycle. The implications are most easily illustrated when demand varies but in a predictable way such that only costs are uncertain. After a period with low demand, firms' willingness to accept risk will be low, and this will soften competition in the sense that firms raise prices or reduce their quantities. Conversely,

\footnotetext{
${ }^{27}$ Predictions based on fixed costs do not apply directly as the following example illustrates. Assume that we observe a number of local markets within the same industry with the same marginal cost uncertainty, and that markets differ only in the amount of fixed costs firms must incur. A static prediction (i.e. taking the number of firms as given) from risk-averse behaviour is that prices are higher in the markets with higher fixed costs. However, a finding of higher prices is also consistent with a free-entry equilibrium with risk neutral firms.
} 
in booms competition among risk-averse firms will be fiercer with, relatively, lower prices or higher quantities. In markets with cost uncertainty, risk aversion thus produces a distinct pattern of prices and quantities over the business cycle. In particular, there will also be a counter-cyclical tendency in price-cost margins. However, the same statement can not be made for demand uncertainty without information on the nature of competition. This relates to a long ranging debate on whether the intensity of competition is pro- or counter-cyclical. Some of the alternative explanations for why margins can have a counter-cyclical tendency include the temptation to deviate from implicitly collusive arrangements in booms (Rotemberg and Saloner, 1986); inflows of new customers in booms (Bils, 1989); and liquidity constraints in recessions (Chevalier and Scharfstein, 1996, and Gottfries, 1991). The test of risk aversion against the set of alternatives would rely on differences in the pattern of margins over the business cycle between markets with significant cost uncertainty and others markets. 


\section{References}

Appelbaum, E., and E. Katz, 1986, Measures of risk aversion and comparative statics of industry equilibrium, American Economic Review 76:524-529.

Baron, D. P., 1970, Price uncertainty, utility, and industry equilibrium in pure competition, International Economic Review 11:463-480.

Baron, D. P., 1971, Demand uncertainty and imperfect competition, International Economic Review 12:196-208.

Bils, M., 1989, Pricing in a customer market, Quarterly Journal of Economics, 104:699-714.

Borenstein, S., and A. Shepard, 1996, Dynamic pricing in retail gasoline markets, Rand Journal of Economics 27: 429-451.

Bresnahan, T., 1989, Empirical Studies of Industries with Market Power, in R. Schmalensee and R. D. Willig (eds.), Handbook of Industrial Organization Vol. 2, (Elsevier Science Publishers B.V.).

Bughin, J., 1999, Oligopoly profit-sharing contracts and the firm's systematic risk, European Economic Review 43:549-558.

Bulow, J., J. Geanakopolos, and P. Klemperer, 1985, Multimarket oligopoly: strategic substitutes and complements, Journal of Political Economy 93:488-511.

Chevalier, J. A., and D. S. Scharfstein, 1996, Capital-market imperfections and countercyclical markups: Theory and evidence, American Economic Review 86:703-725.

Dixit, A., 1980, The role of investment in entry deterrence, Economic Journal 90:95-106.

Dixit, A., 1986, Comparative statics for oligopoly, International Economic Review 27:107122.

Eeckhoudt, L., and C. Gollier, 1995, Risk - evaluation, management and sharing, (Harvester Wheatsheaf).

Eeckhoudt, L., C. Gollier, and H. Schlesinger, 1996, Changes in background risk and risk taking behavior, Econometrica 64:683-689.

Eldor, R., and I. Zilcha ,1990, Oligopoly, uncertain demand, and forward markets, Journal of Economics and Business 42:17-26.

Froot, K. A., D. S. Scharfstein, and J. C. Stein, 1993, Risk management: Coordinating corporate investment and financial policies, Journal of Finance 48:1629-1658.

Géczy, C., B. A. Minton, and C. Schrand, 1997, Why firms use currency derivatives, Journal of Finance 52:1323-1354.

Genesove, D., and P. Mullin, 1998, Testing static oligopoly models: conduct and cost in the sugar industry, 1890-1914, Rand Journal of Economics 28:355-377. 
Glazer, J., 1994, The strategic effects of long-term debt in imperfect competition, Journal of Economic Theory 62:428-443.

Gollier, C., and J. W. Pratt, 1996, Risk vulnerability and the tempering effect of background risk, Econometrica 64: 1109-1123.

Gottfries, N., 1991, Customer markets, credit market imperfections and real price rigidity, Economica 58: 317-323.

Harris, F. H. Deb., 1986, Market structure and price-cost performance under endogenous profit risk, Journal of Industrial Economics 35:35-59.

Haruna, S., 1996, Industry equilibrium, uncertainty, and futures markets, International Journal of Industrial Organization 14:53-70.

Holthausen, D. M., 1979, Kinky demand, risk aversion and price leadership, International Economic Review 20:341-348.

Huang, C-F., and R. H. Litzenberger, 1988, Foundations of financial economics, (Elsevier Science Publishers B.V.).

Hughes, J. S., and J. L. Kao, 1997, Strategic forward contracting and observability, International Journal of Industrial Organization 16:121-133.

Hviid, M., 1989, Risk-averse duopolists and voluntary information transmission, Journal of Industrial Economics 38:49-64.

Ingersoll, J. E., 1987, Theory of financial decision making, (Rowman and Littlefield Publishers Inc.).

Kao, J. L., and J. S. Hughes, 1993, Note on risk aversion and sharing of firm-specific information in duopolies, Journal of Industrial Economics 41:103-112.

Kimball, M. S., 1993, Standard risk aversion, Econometrica 61:589-611.

Klemperer, P., and M. A. Meyer, 1986, Price competition vs. quantity competition: the role of uncertainty, Rand Journal of Economics 17:618-638.

Klemperer, P., and M. A. Meyer, 1989, Supply function equilibria in oligopoly under uncertainty, Econometrica 57: 1243-1277.

Leland, H., 1972, Theory of the firm facing random demand, American Economic Review 62:278-291.

Lieberman, M. B., 1987, Excess capacity as a barrier to entry: An empirical appraisal, Journal of Industrial Economics 35:607-627.

Mai, C., C. Yeh, and S. Suwanakul, 1993, Price uncertainty and production-location decisions under free entry oligopoly, Journal of Regional Science 33:531-545.

Nance, D. R., C. W. Smith, Jr, and C. W. Smithson, 1993, On the determinants of corporate hedging, Journal of Finance 48:267-284. 
Raith, M., 1996, A general model of information sharing in oligopoly, Journal of Economic Theory 71: 260-288.

Rotemberg, J. J. and G. Saloner, 1986, A supergame-theoretic model of price wars during booms, American Economic Review 76: 390-407.

Rubinstein, M., 1976, The valuation of uncertain income streams and the pricing of options, Bell Journal of Economics and Management Science 7:407-425.

Sandmo, A., 1971, On the theory of the competitive firm under price uncertainty, American Economic Review 61:65-73.

Schmalensee, R., 1989, Inter-industry studies of structure and performance, in R. Schmalensee and R. D. Willig (eds.), Handbook of Industrial Organization Vol. 2, (Elsevier Science Publishers B.V.).

Tessiotore, A., 1994, Market segmentation and oligopoly under uncertainty, Journal of Economics and Business 46:65-76.

Tirole, J., 1988, The theory of industrial organisation, (MIT Press).

Tufano, P., 1996, Who manages risk? An empirical examination of risk management practices in the gold mining industry, Journal of Finance 51:1097-1137.

Wambach, A., 1999, Bertrand competition under cost uncertainty, International Journal of Industrial Organization 17. 


\section{Appendix 1}

First-order condition with (approximately) normally distributed profits and marginal profits

The purpose of this appendix is to provide an alternative formulation of a risk-averse firm's first-order condition that in some applications can prove more tractable. As shown in Section 2, the first-order condition can be written as

$$
E \pi_{s^{i}}^{i}+\frac{\operatorname{Cov}\left(U_{\pi^{i}}^{i}, \pi_{s^{i}}^{i}\right)}{E U_{\pi^{i}}^{i}}=0 .
$$

Compared to the main text, the new assumption is that $\pi^{i}$ and $\pi_{s^{i}}^{i}$ are bivariate normal

$$
\pi^{i}, \pi_{s^{i}}^{i} \in N\left(E \pi^{i}, E \pi_{s^{i}}^{i}, \sigma_{\pi^{i}}^{2}, \sigma_{\pi_{s^{i}}^{i}}^{2}, \rho^{i}\right)
$$

where $\rho^{i}$ is the correlation coefficient defined by

$$
\rho^{i}=\frac{\operatorname{Cov}\left(\pi^{i}, \pi_{s^{i}}^{i}\right)}{\sigma_{\pi^{i}} \sigma_{\pi_{s^{i}}^{i}}}
$$

Note that this is a different $\rho^{i}$ than that discussed in the main text, which just referred to a correlation between profits and marginal profits - not the correlation coefficient in (A1.2).

It is well known that the assumption of normality of payoffs gives a mean - variance model, since third and higher moments are zero. However, under the assumption of normal distribution (and any other distribution with unbounded support) there is a positive probability that profits and marginal profits are either infinitely positive or negative. Nevertheless, even if the distribution is not exactly normal it may for practical purposes be a good approximation to the true distribution over the relevant range. ${ }^{28}$

\footnotetext{
28 Normality of the density function is the standard defence of the mean - variance analysis in portfolio choice even though stock prices are truncated at zero, see e.g. Ingersoll (1987 p. 95-97) and Huang and Litzenberger (1988 p. 61-62). To numerically calculate the equilibrium strategies under the assumption that the distribution is approximately normal, it is necessary to truncate the distribution at some level.
} 
Under (A1.1), Steins lemma can be applied by which ${ }^{29}$

$$
\operatorname{Cov}\left(U_{\pi^{i}}^{i}, \pi_{s^{i}}^{i}\right)=E U_{\pi^{i} \pi^{i}}^{i} \operatorname{Cov}\left(\pi^{i}, \pi_{s^{i}}^{i}\right)
$$

The Arrow-Pratt measure of global absolute risk aversion is

$$
r^{i}\left(W^{i}\right)=-\frac{E U_{\pi^{i} \pi^{i}}^{i}}{E U_{\pi^{i}}^{i}} .
$$

Combining (2), (A1.3), and (A1.4) yields the first-order conditions

$$
V_{s^{i}}^{i}=E \pi_{s^{i}}^{i}\left(s^{i}, s^{j}\right)-r^{i}\left(W^{i}\right) \operatorname{Cov}\left(\pi^{i}\left(s^{i}, s^{j}\right), \pi_{s^{i}}^{i}\left(s^{i}, s^{j}\right)\right)=0 .
$$

To my knowledge, no previous works have stated the first-order conditions as (A1.5). In words, the first-order condition states that the expected marginal operating profit should equal the absolute risk aversion times the covariance of profits and marginal profits. The ArrowPratt measure of absolute risk aversion is positive under the assumption of risk aversion (and zero under risk-neutrality). Note that for $r^{i}\left(W^{i}\right)>0$ the expected marginal profit has to be strictly positive to satisfy (A1.5) when $\rho^{i}>0$, and strictly negative when $\rho^{i}<0$. For additional results see Asplund (1995).

The drawback of (A1.5) is, apart for its reliance on the normal distribution, is that $r^{i}\left(W^{i}\right)$ can't be used to compare the risk aversion generated by different concave utility functions, as shown by Kihlstrom et al. (1981). To compare one needs to impose certain restrictions on the class of utility functions.

\footnotetext{
${ }^{29}$ The theorem, proved by Rubinstein (1976), states that if $\mathrm{x}$ and $\mathrm{y}$ are bivariate normally distributed, and $\mathrm{g}(\mathrm{y})$ is at least once differentiable then $\operatorname{Cov}(x, g(y))=\operatorname{Eg}_{y}(y) \operatorname{Cov}(x, y)$. See e.g., Huang and Litzenberger (1988 p. 101).
} 


\section{Appendix 2}

This appendix shows, by way of a simple example based on (I1) and (I2) in section 3.1.1, that a SSD relation can be sufficient to make inferences on the best response functions.

Part 1: Relation between best response strategies when $F_{0}\left(\pi^{i}\right) \operatorname{SSD} F_{1}\left(\pi^{i}\right)$, and $F_{0}\left(\pi^{i}\right)$ is degenerate.

The important parts of profit functions (I1) and (I2) can be rewritten as

$$
\begin{aligned}
& \pi^{i}\left(s^{i}, s^{j}, \varepsilon\right)=s^{i}\left(b_{0}+b_{1} s^{i}+b_{2} s^{j}-c\right) \\
& \pi^{i}\left(s^{i}, s^{j}, \varepsilon\right)=\left(s^{i}-c\right)\left(b_{0}+b_{1} s^{i}+b_{2} s^{j}\right),
\end{aligned}
$$

where $\varepsilon$ refers to either $b_{0}>0, b_{1}<0, c>0$, or $b_{2}<0$ in (I1') and $b_{2}>0$ in (I2'). To reason behind the reformulation is to assure that profit is increasing the realisation of $\varepsilon, \pi_{\varepsilon}^{i}\left(s^{i}, s^{j}, \varepsilon\right)>0$.

The marginal profits profits are then

$$
\begin{aligned}
& \pi_{s^{i}}^{i}\left(s^{i}, s^{j}, \mathcal{\varepsilon}\right)=\left(b_{0}+2 b_{1} s^{i}+b_{2} s^{j}-c\right) \\
& \pi_{s^{i}}^{i}\left(s^{i}, s^{j}, \mathcal{E}\right)=\left(b_{0}+b_{1}\left(2 s^{i}-c\right)+b_{2} s^{j}\right) .
\end{aligned}
$$

Introduce a new distribution of uncertainty $\varepsilon^{\prime}=\varepsilon+z$ with $E z=0$ and Ez|c. The profit functions corresponding to (I1') and (I2') can, due to linearity in $\varepsilon$, be formulated as

$$
\pi^{i}\left(s^{i}, s^{j}, \varepsilon^{\prime}\right)=\pi^{i}\left(s^{i}, s^{j}, \varepsilon+z\right)=\pi^{i}\left(s^{i}, s^{j}, \varepsilon\right)+\kappa^{i}\left(s^{i}, s^{j}, z\right),
$$

and the marginal profit

$$
\pi_{s^{i}}^{i}\left(s^{i}, s^{j}, \varepsilon^{\prime}\right)=\pi_{s^{i}}^{i}\left(s^{i}, s^{j}, \varepsilon\right)+\kappa_{s^{i}}^{i}\left(s^{i}, s^{j}, z\right)
$$

$\kappa$ is a function that is independent of $\varepsilon$, but whose functional form depends on where uncertainty enters (i.e., whether $\mathrm{b}_{0}, \mathrm{~b}_{1}, \mathrm{~b}_{2}$, or $\mathrm{c}$ is uncertain). Note that $\kappa_{z}^{i}\left(s^{i}, s^{j}, z\right)>0$.

For ease of reference, firm i's first order conditions, as stated in Section 3.3.2, are

$$
E U_{\pi^{i}}^{i}\left[w^{i}+\pi^{i}\left(s^{i}, s^{j}, \mathcal{E}\right)\right] \pi_{s^{i}}^{i}\left(s^{i}, s^{j}, \mathcal{E}\right)=0
$$




$$
E U_{\pi^{i}}^{i}\left[w^{i}+\pi^{i}\left(s^{i}, s^{j}, \varepsilon+z\right)\right] \pi_{s^{i}}^{i}\left(s^{i}, s^{j}, \varepsilon+z\right)=0
$$

To simplify notation, suppress the strategies in the functions and concentrate on the realisations. Further, consider the simplest case where $\varepsilon$ can take only two values $\underline{\varepsilon}$ and $\bar{\varepsilon}>\underline{\varepsilon}$. Let $z$ also have two outcomes, $z^{-}<0$ and $z^{+}>z^{-} .30$ Then it follows that

$$
E \kappa^{i}(z)=E \kappa^{i}\left(z^{-}\right)+E \kappa^{i}\left(z^{+}\right)=0
$$

and

$$
E \kappa_{s^{i}}^{i}(z)=E \kappa_{s^{i}}^{i}\left(z^{-}\right)+E \kappa_{s^{i}}^{i}\left(z^{+}\right)=0 .
$$

By conditioning on the value of $\varepsilon$, the conditional best-response functions are $b^{i}\left(s^{j} \mid \varepsilon\right)$ and $\hat{b}^{i}\left(s^{j} \mid \varepsilon\right)$. In this case firm i faces no uncertainty with profit function $\pi^{i}\left(s^{i}, s^{j}, \varepsilon\right)$ (i.e., $F_{0}\left(\pi^{i}\right)$ is degenerate) while the uncertainty in $z$ remains with $\pi^{i}\left(s^{i}, s^{j}, \varepsilon^{\prime}\right)$. The first-order condition (4), conditional on $\varepsilon$, is then simply

$$
E U_{\pi^{i}}^{i}[\pi(\varepsilon)] \pi_{s^{i}}^{i}(\varepsilon)=0 \Rightarrow \pi_{s^{i}}^{i}(\varepsilon)=0 .
$$

It will be proved that $b^{i}\left(s^{j} \mid \varepsilon\right)$ can not satisfy (5), therefore we make the assumption that $\hat{b}^{i}\left(s^{j} \mid \varepsilon\right)=b^{i}\left(s^{j} \mid \varepsilon\right)$ in which case (5) is

$$
\begin{aligned}
& E U_{\pi^{i}}^{i}\left[\pi^{i}\left(\varepsilon^{\prime}\right)\right] \pi_{s^{i}}^{i}\left(\varepsilon^{\prime}\right)=E U_{\pi^{i}}^{i}\left[\pi^{i}(\varepsilon)+\kappa^{i}(z)\right]\left(\pi_{s^{i}}^{i}(\varepsilon)+\kappa_{s^{i}}^{i}(z)\right)= \\
& E U_{\pi^{i}}^{i}\left[\pi^{i}(\varepsilon)+\kappa^{i}(z)\right] \kappa_{s^{i}}^{i}(z)
\end{aligned},
$$

where the second equality follows from (A2.5). By partitioning (A2.6)

$$
\begin{aligned}
& E U_{\pi^{i}}^{i}\left[\pi^{i}(\varepsilon)+\kappa^{i}(z)\right] \kappa_{s^{i}}^{i}(z)= \\
& \left.E U_{\pi^{i}}^{i}\left[\pi^{i}(\varepsilon)+\kappa^{i}\left(z^{-}\right)\right] \kappa_{s^{i}}^{i}\left(z^{-}\right)+E U_{\pi^{i}}^{i}\left[\pi^{i}(\varepsilon)+\kappa^{i}\left(z^{+}\right)\right] \kappa_{s^{i}}^{i}\left(z^{+}\right)\right)= \\
& \left.U_{\pi^{i}}^{i}\left[\pi^{i}(\varepsilon)+E \kappa^{i}\left(z^{-}\right)\right] E \kappa_{s^{i}}^{i}\left(z^{-}\right)+U_{\pi^{i}}^{i}\left[\pi^{i}(\varepsilon)+E \kappa^{i}\left(z^{+}\right)\right] E \kappa_{s^{i}}^{i}\left(z^{+}\right)\right)
\end{aligned}
$$

\footnotetext{
30 In addition it is assumed that the z's are smaller, in absolute terms, the than $\varepsilon^{\prime} \mathrm{s}$ in order to assure an unambiguous ranking of the $\pi$ 's in $\mathrm{z}$ and $\varepsilon$.
} 
where the second equality follows from the fact that there is no uncertainty in the parts. Here, note why the problem of comparing (4) and (5) can not be treated as a background risk: the distributions of $\kappa^{i}\left(s^{i}, s^{j}, z\right)$ and $\kappa_{s^{i}}^{i}\left(s^{i}, s^{j}, z\right)$ depend on the choice of $s^{i}$, as opposed to the background risk whose distribution was independent of $s^{i}$.

Next, applying (A2.3) and (A2.4) to (A2.7) yields

$$
\begin{aligned}
& \left.U_{\pi^{i}}^{i}\left[\pi^{i}(\varepsilon)+E \kappa^{i}\left(z^{-}\right)\right] E \kappa_{s^{i}}^{i}\left(z^{-}\right)+U_{\pi^{i}}^{i}\left[\pi^{i}(\varepsilon)+E \kappa^{i}\left(z^{+}\right)\right] E \kappa_{s^{i}}^{i}\left(z^{+}\right)\right)= \\
& \left(U_{\pi^{i}}^{i}\left[\pi^{i}(\varepsilon)+E \kappa^{i}\left(z^{-}\right)\right]-U_{\pi^{i}}^{i}\left[\pi^{i}(\varepsilon)-E \kappa^{i}\left(z^{-}\right)\right]\right) E \kappa_{s^{i}}^{i}\left(z^{-}\right)
\end{aligned}
$$

Now consider the relation between $\kappa^{i}(z)$ and $\kappa_{s^{i}}^{i}(z)$. By construction, higher $z$ increases $\kappa^{i}(z)$. Hence there are two cases: 1) $\kappa_{s^{i}}^{i}(z)$ increases in z, or 2) $\kappa_{s^{i}}^{i}(z)$ decreases in $\mathrm{z}$. The first case corresponds to $\rho^{i}>0$ (a positive correlation between profits and marginal profits) and the second to $\rho^{i}<0$. Take the first case as an example and note that $E \kappa^{i}\left(z^{-}\right)<0$ we get

$$
\pi^{i}(\varepsilon)+E \kappa^{i}\left(z^{-}\right)<\pi^{i}(\varepsilon)-E \kappa^{i}\left(z^{-}\right) \Rightarrow U_{\pi^{i}}^{i}\left[\pi^{i}(\varepsilon)+E \kappa^{i}\left(z^{-}\right)\right]>U_{\pi^{i}}^{i}\left[\pi^{i}(\varepsilon)-E \kappa^{i}\left(z^{-}\right)\right] .
$$

By $E \kappa_{s^{i}}^{i}\left(z^{-}\right)<0$ we have

$$
\left(U_{i}^{i}\left[\pi^{i}(\varepsilon)+E \kappa^{i}\left(z^{-}\right)\right]-U_{i}^{i}\left[\pi^{i}(\varepsilon)-E \kappa^{i}\left(z^{-}\right)\right]\right) E \kappa_{s^{i}}^{i}\left(z^{-}\right)<0 .
$$

Hence, we have showed that $\hat{b}^{i}\left(s^{j} \mid \varepsilon\right)=b^{i}\left(s^{j} \mid \varepsilon\right)$ results in a negative first order condition (A2.6) for $\rho^{i}>0$. It is straightforward to verify that concavity of the profit function requires that $\hat{b}^{i}\left(s^{j} \mid \varepsilon\right)<b^{i}\left(s^{j} \mid \varepsilon\right)$ when $\rho^{i}>0$. The only difference for $\rho^{i}<0$ is that $E \kappa_{s^{i}}^{i}\left(z^{-}\right)>0$, which implies that $\hat{b}^{i}\left(s^{j} \mid \varepsilon\right)>b^{i}\left(s^{j} \mid \varepsilon\right)$. Q.E.D. 
Part 2: Relation between best response strategies when $F_{0}\left(\pi^{i}\right) \operatorname{SSD} F_{1}\left(\pi^{i}\right)$, and $F_{0}\left(\pi^{i}\right)$ is non-degenerate.

As in the previous part, we wish to show that $b^{i}\left(s^{j}\right)$ which satisfy (4) can't satisfy the firstorder condition (5) therefore assume that it does. Partitioning the first-order condition (5) gives

$$
\begin{aligned}
& E U_{\pi^{i}}^{i}\left[\pi^{i}\left(\mathcal{\varepsilon}^{\prime}\right)\right] \pi_{s^{i}}^{i}\left(\varepsilon^{\prime}\right)=E U_{\pi^{i}}^{i}\left[\pi^{i}(\varepsilon)+\kappa^{i}(z)\right]\left(\pi_{s^{i}}^{i}(\varepsilon)+\kappa_{s^{i}}^{i}(z)\right)= \\
& E U_{\pi^{i}}^{i}\left[\pi^{i}(\underline{\varepsilon})+\kappa^{i}\left(z^{-}\right)\right]\left(\pi_{s^{i}}^{i}(\underline{\varepsilon})+\kappa_{s^{i}}^{i}\left(z^{-}\right)\right)+E U_{\pi^{i}}^{i}\left[\pi^{i}(\underline{\varepsilon})+\kappa^{i}\left(z^{+}\right)\right]\left(\pi_{s^{i}}^{i}(\underline{\varepsilon})+\kappa_{s^{i}}^{i}\left(z^{+}\right)\right)+, \\
& E U_{\pi^{i}}^{i}\left[\pi^{i}(\bar{\varepsilon})+\kappa^{i}\left(z^{-}\right)\right]\left(\pi_{s^{i}}^{i}(\bar{\varepsilon})+\kappa_{s^{i}}^{i}\left(z^{-}\right)\right)+E U_{\pi^{i}}^{i}\left[\pi^{i}(\bar{\varepsilon})+\kappa^{i}\left(z^{+}\right)\right]\left(\pi_{s^{i}}^{i}(\bar{\varepsilon})+\kappa_{s^{i}}^{i}\left(z^{+}\right)\right)
\end{aligned}
$$

Applying (A2.3) and (A2.4), (A2.11) is equivalent to

$$
\begin{aligned}
& U_{\pi^{i}}^{i}\left[E \pi^{i}(\underline{\varepsilon})+E \kappa^{i}\left(z^{-}\right)\right]\left(E \pi_{s^{i}}^{i}(\underline{\varepsilon})+E \kappa_{s^{i}}^{i}\left(z^{-}\right)\right)+U_{\pi^{i}}^{i}\left[E \pi^{i}(\underline{\varepsilon})-E \kappa^{i}\left(z^{-}\right)\right]\left(E \pi_{s^{i}}^{i}(\underline{\varepsilon})-E \kappa_{s^{i}}^{i}\left(z^{-}\right)\right)+ \\
& U_{\pi^{i}}^{i}\left[E \pi^{i}(\overline{\bar{\varepsilon}})+E \kappa^{i}\left(z^{-}\right)\right]\left(E \pi_{s^{i}}^{i}(\overline{\bar{\varepsilon}})+E \kappa_{s^{i}}^{i}\left(z^{-}\right)\right)+U_{\pi^{i}}^{i}\left[E \pi^{i}(\overline{\bar{\varepsilon}})-E \kappa^{i}\left(z^{-}\right)\right]\left(E \pi_{s^{i}}^{i}(\overline{\bar{\varepsilon}})-E \kappa_{s^{i}}^{i}\left(z^{-}\right)\right)
\end{aligned}
$$

After some manipulations (A2.12) can be written as

$$
\begin{aligned}
& E \kappa_{s^{i}}^{i}\left(z^{-}\right)\left(U_{\pi^{i}}^{i}\left[E \pi^{i}(\underline{\varepsilon})+E \kappa^{i}\left(z^{-}\right)\right]-U_{\pi^{i}}^{i}\left[E \pi^{i}(\underline{\varepsilon})-E \kappa^{i}\left(z^{-}\right)\right]\right)+ \\
& E \kappa_{s^{i}}^{i}\left(z^{-}\right)\left(U_{\pi^{i}}^{i}\left[E \pi^{i}(\bar{\varepsilon})+E \kappa^{i}\left(z^{-}\right)\right]-U_{\pi^{i}}^{i}\left[E \pi^{i}(\bar{\varepsilon})-E \kappa^{i}\left(z^{-}\right)\right]\right)+ \\
& E \pi_{s^{i}}^{i}(\underline{\varepsilon})\left(U_{\pi^{i}}^{i}\left[E \pi^{i}(\underline{\varepsilon})+E \kappa^{i}\left(z^{-}\right)\right]+U_{\pi^{i}}^{i}\left[E \pi^{i}(\underline{\varepsilon})-E \kappa^{i}\left(z^{-}\right)\right]\right)+ \\
& E \pi_{s^{i}}^{i}(\bar{\varepsilon})\left(U_{\pi^{i}}^{i}\left[E \pi^{i}(\bar{\varepsilon})+E \kappa^{i}\left(z^{-}\right)\right]+U_{\pi^{i}}^{i}\left[E \pi^{i}(\bar{\varepsilon})-E \kappa^{i}\left(z^{-}\right)\right]\right)
\end{aligned}
$$

Again there are two cases depending on the sign of $\rho^{i}$. To analyse (A2.13), note that $E \kappa^{i}\left(z^{-}\right)<0$. For $\rho^{i}>0, E \kappa_{s^{i}}^{i}\left(z^{-}\right)<0, E \pi_{s^{i}}^{i}(\bar{\varepsilon})>0$, and $E \pi_{s^{i}}^{i}(\underline{\varepsilon})<0$. It follows then that each row in (A2.13) is negative and so is, of course, the entire expression. Hence, we have proved that $b^{i}\left(s^{j}\right)$ can't satisfy (5). For $\rho^{i}>0 E \kappa_{s^{i}}^{i}\left(z^{-}\right)>0, E \pi_{s^{i}}^{i}(\bar{\varepsilon})<0$, and $E \pi_{s^{i}}^{i}(\underline{\varepsilon})>0$ such that each row is positive.

The conclusion from applying the concavity of the profit function mirrors that from the conditional best-response functions: $b^{i}\left(s^{j}\right)>\hat{b}^{i}\left(s^{j}\right)$ when $\rho^{i}>0$ and $b^{i}\left(s^{j}\right)<\hat{b}^{i}\left(s^{j}\right)$ when $\rho^{i}<0$. Q.E.D. 
Figure 1A. Best response functions and Nash equilibria for strategic substitutes. The best response function $\hat{b}^{i}\left(s^{j}\right)$ corresponds to a more risk-averse firm i than $b^{i}\left(s^{j}\right)$.

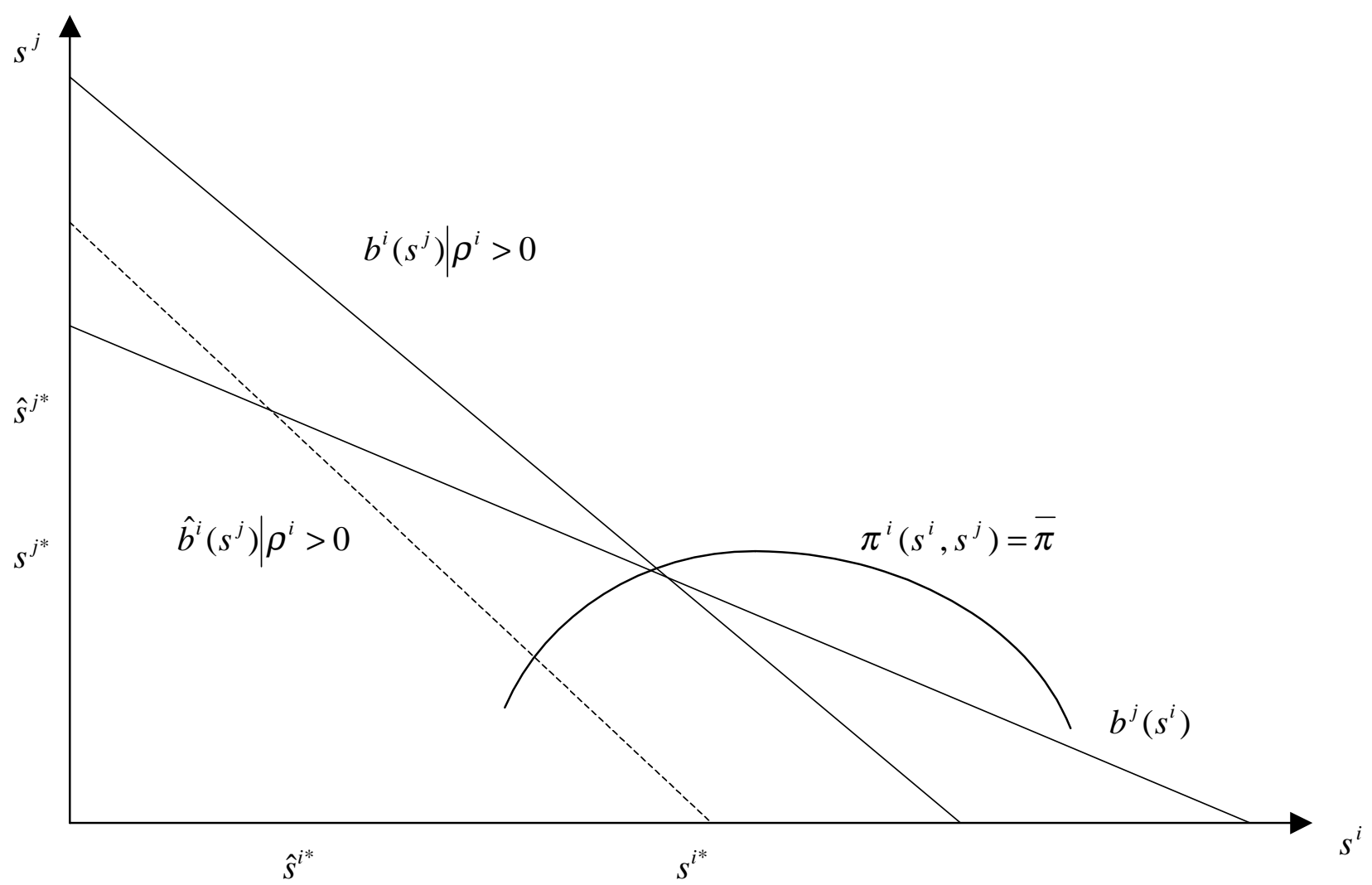


Figure 1B. Best response functions and Nash equilibria for strategic complements. The best response functions $\hat{b}^{i}\left(s^{j}\right)$ correspond to a more risk-averse firm i than $b^{i}\left(s^{j}\right)$.

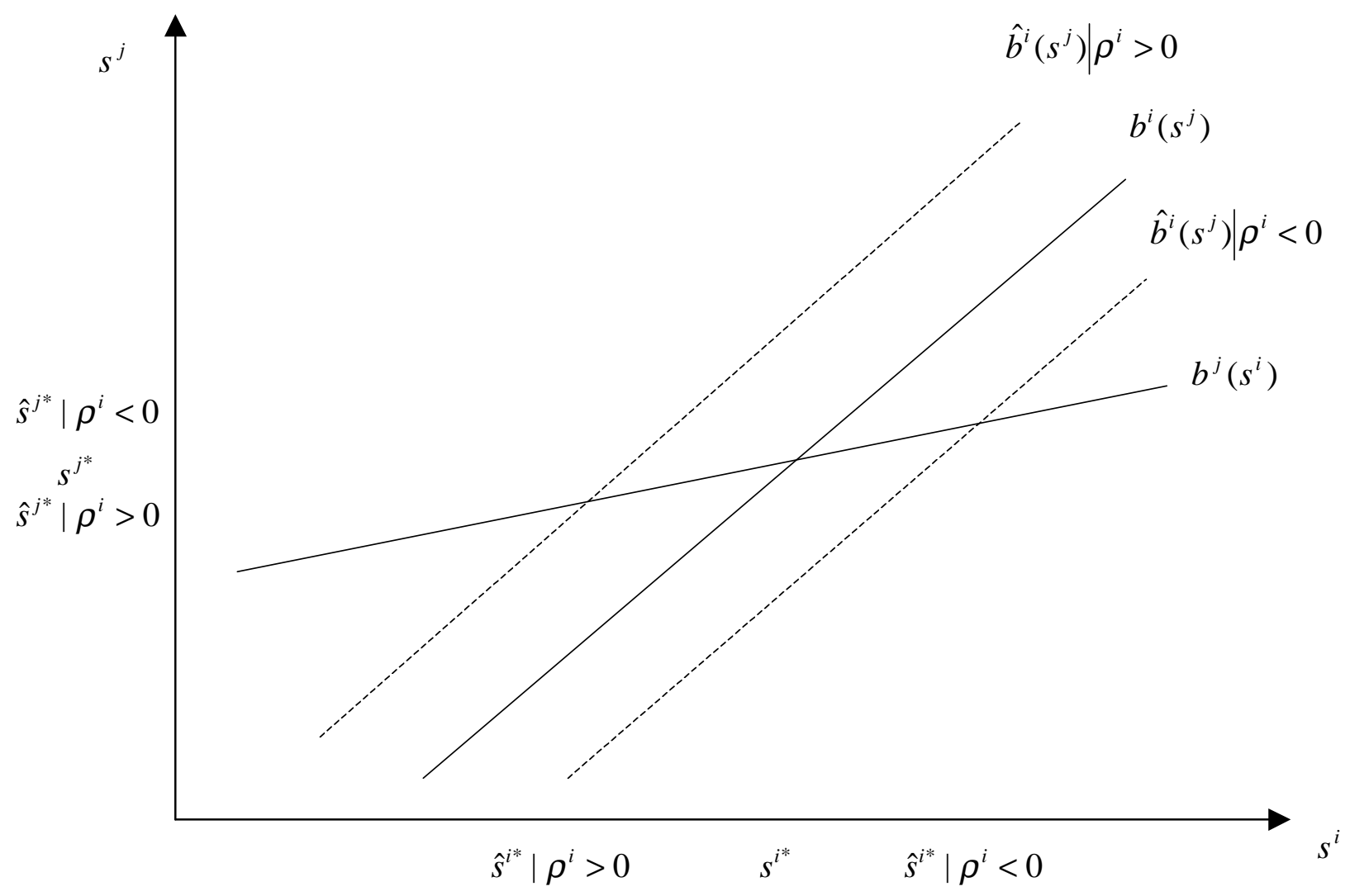

